\title{
Hydrogen Storage Properties of B- and $\mathrm{N}$-Doped Microporous Carbon
}

\author{
Lifeng Wang, Frances H. Yang, and Ralph T. Yang \\ Dept. of Chemical Engineering, University of Michigan, Ann Arbor, MI 48109 \\ DOI 10.1002/aic.11851 \\ Published online May 26, 2009 in Wiley InterScience (www.interscience.wiley.com).
}

\begin{abstract}
$A B$ - and $N$-doped microporous carbon has been synthesized via a substitution reaction. The obtained carbon exhibited much higher surface area than the previously reported $B$ - and $N$-doped carbon. The hydrogen storage measurements indicated that the $B$-and $N$-doped microporous carbon had a 53\% higher storage capacity than the carbon materials with similar surface areas. Furthermore, hydrogen storage via spillover was studied on Ru-supported B-and $N$-doped microporous carbon and a storage capacity of $1.2 \mathrm{wt} \%$ at $298 \mathrm{~K}$ and $10 \mathrm{MPa}$ was obtained, showing an enhancement factor of 2.2. Ab initio molecular orbital calculations were also performed for the binding energies between the spiltover hydrogen atom and various sites on the doped carbon. The theoretical calculations can explain the experimental results well, which also shed light on the most favorable and possible sites with which the spiltover hydrogen atoms bind. (C) 2009 American Institute of Chemical Engineers AIChE J, 55: 1823-1833, 2009
\end{abstract}

Keywords: microporous carbon, boron- and nitrogen-doped carbon, hydrogen storage, hydrogen spillover, hydrogen binding on carbon

\section{Introduction}

In recent years, various carbon materials such as activated carbon (AC), carbon nanotubes (CNTs), microporous carbon and mesoporous carbon have been studied extensively for a variety of applications. ${ }^{1-12}$ Among these studies, there has been growing interest in synthesis of B- and/or N-doped carbon materials due to their unique electronic, mechanical, optical and adsorption properties compared with pure carbon materials. ${ }^{13-38}$ B- and N-doped carbon nanotubes (BCN nanotubes), including single-walled carbon nanotubes (SWNTs), double-walled carbon nanotubes (DWNTs) and multi-walled carbon nanotubes (MWNTs) have been synthesized by various methods including arc-discharge, ${ }^{25,26}$ laser ablation, ${ }^{27,28}$ substitution reaction, ${ }^{29-31}$ and chemical vapor deposition (CVD) ${ }^{32-35} \mathrm{~B}$ - and N-doped amorphous carbon ${ }^{36}$ and carbon film ${ }^{37}$ have been prepared by carbonization of

Additional Supporting Information may be found in the online version of this article.

Correspondence concerning this article should be addressed to R. T. Yang at yang@umich.edu.

(C) 2009 American Institute of Chemical Engineers polymer precursor containing boron and nitrogen. Recently, Vinu et al. reported the synthesis of B- and N-doped mesoporous carbon by using a substitution reaction. ${ }^{38}$ However, these B- and N-doped carbon materials displayed relatively low-surface areas, and there has been no report on the preparation of $\mathrm{B}-$ and $\mathrm{N}$-doped microporous carbon. Developing $\mathrm{B}$ - and $\mathrm{N}$-doped carbon materials with different pore structures and a high-surface area is highly desirable.

Herein, we report on the synthesis of a B- and N-doped microporous carbon with a high-surface area. The B- and Ndoped microporous carbon was prepared via a substitution reaction involving a plain microporous carbon with a highsurface area and porosity as the template, which facilitated the substitution reaction with the reactant gases of boron oxide and ammonia. More importantly, the obtained B- and Ndoped microporous carbon showed a 53\% higher hydrogen storage capacity than the corresponding pure carbon materials that had the same surface area. Furthermore, doping of $\mathrm{Ru}$ particles on $\mathrm{B}$ - and $\mathrm{N}$-doped microporous carbon significantly enhanced its hydrogen uptake by a factor of 2.2 due to hydrogen spillover effect. These results can be explained well by our ab initio molecular orbital calculations. 


\section{Experimental Methods}

Synthesis

Plain Microporous Carbon. Microporous carbon derived from zeolite EMC-2 was prepared according to a procedure similar to that proposed by Kyotani and Parmentier. ${ }^{4,8}$ EMC2 was degassed in a flask for $12 \mathrm{~h}$ at $473 \mathrm{~K}$, then furfuryl alcohol (FA) was introduced into the flask at a reduced pressure. The mixture of EMC-2 and FA was stirred overnight in a He flow and then filtered. The polymerization of FA in EMC-2 was carried out by heating the composite under a flow of $\mathrm{He}$ at $353 \mathrm{~K}$ for $24 \mathrm{~h}$, then at $423 \mathrm{~K}$ for $8 \mathrm{~h}$. The EMC-2/PFA composite was placed in a vertical quartz tube and heated to $973 \mathrm{~K}$ under a $\mathrm{N}_{2}$ flow. When the temperature reached $973 \mathrm{~K}$, propylene gas $\left(2 \%\right.$ in $\mathrm{N}_{2}$ by volume; flow rate: $150 \mathrm{~cm}^{3} / \mathrm{min}$ ) was passed through the tube for $15 \mathrm{~h}$. After the CVD treatment, the composite was further heated at $1173 \mathrm{~K}$ for $2 \mathrm{~h}$ under a flow of $\mathrm{N}_{2}$. The obtained EMC-2/ carbon composite was treated in $\mathrm{HF}$ solution (40\%) for $24 \mathrm{~h}$, and, subsequently, refluxed by concentrated $\mathrm{HCl}$ solution for $4 \mathrm{~h}$ to dissolve the template of EMC-2. The resulting microporous carbon was collected by filtration and washing with distilled water.

$B$ - and $N$-doped Microporous Carbon. Typically, equal mass amounts of microporous carbon and $\mathrm{B}_{2} \mathrm{O}_{3}$ were heated together in an atmosphere of dilute ammonia (1\% in $\mathrm{He}$ ) at $1423 \mathrm{~K}$ for $1 \mathrm{~h}$. The heating rate was $60 \mathrm{~K} / \mathrm{min}$.

6 wt \% Ru Supported on B- and N-doped Microporous Carbon. Typically, $200 \mathrm{mg}$ of well-dried B- and N-doped microporous carbon was dispersed in $20 \mathrm{~mL}$ of acetone and was stirred for $0.5 \mathrm{~h}$ in a flask at room-temperature. $5 \mathrm{~mL}$ of acetone was mixed with $800 \mathrm{mg} \mathrm{Ru}(\mathrm{NO})(\mathrm{NO} 3)_{\mathrm{x}}(\mathrm{OH})_{\mathrm{y}}$ aqua (1.5 wt \% Ru content), which was slowly added to the aforementioned solution under vigorous agitation. The mixture was subjected to ultrasonication $(100 \mathrm{~W}, 42 \mathrm{kHz})$ for $1 \mathrm{~h}$ and then magnetically stirred at room-temperature for $24 \mathrm{~h}$. After being dried in an oven at $333 \mathrm{~K}$ overnight, the impregnated sample was transferred to a horizontal quartz tube and treated in a $\mathrm{He}$ atmosphere at $1173 \mathrm{~K}$ for $1 \mathrm{~h}$.

Mesoporous Carbon (CMK-3). CMK-3 was synthesized according to the reported procedure. ${ }^{10}$ In a typical run, $1 \mathrm{~g}$ of SBA-15 powder was mixed with an aqueous solution containing $1.25 \mathrm{~g}$ of sucrose, $0.14 \mathrm{~g}$ of $\mathrm{H}_{2} \mathrm{SO}_{4}$, and $5.0 \mathrm{~g}$ of $\mathrm{H}_{2} \mathrm{O}$. The viscous mixture was placed in a drying oven at $373 \mathrm{~K}$ for $6 \mathrm{~h}$, and, subsequently, at $433 \mathrm{~K}$ for $6 \mathrm{~h}$. The treated mixture was mixed again with aqueous solution containing $0.75 \mathrm{~g}$ of sucrose, $0.09 \mathrm{~g}$ of $\mathrm{H}_{2} \mathrm{SO}_{4}$, and $5.0 \mathrm{~g}$ of $\mathrm{H}_{2} \mathrm{O}$. After heating at $433 \mathrm{~K}$ for $6 \mathrm{~h}$ in the drying oven, the mixture was further carbonized at $1173 \mathrm{~K}$ for $4 \mathrm{~h}$ under nitrogen atmosphere. The obtained carbon/SBA-15 composite was washed with hydrofluoric acid to remove SBA-15 template.

\section{Characterization}

Powder X-ray diffraction (XRD) data were recorded on a Rigaku Miniflex diffractometer at $30 \mathrm{kV}, 15 \mathrm{~mA}$ for $\mathrm{Cu} \mathrm{K} \alpha$ $(\lambda=0.1543 \mathrm{~nm})$ radiation. High-resolution transmission electron microscopy (HRTEM) images of the materials were obtained on a JEOL 3011 analytical electron microscope. Electron energy-loss spectroscopy (EELS) spectra were obtained on a JEOL 2010F equipped with a Gatan EELS spectrometer. X-ray photoelectron spectroscopy was recorded on a Kratos Axis ultra XPS spectrometer. Nitrogen adsorption and low-pressure $\mathrm{H}_{2}$ adsorption isotherms (0-1 atm) were measured with a standard static volumetric technique (Micromeritics ASAP 2020 sorptometer). Hydrogen adsorption at $298 \mathrm{~K}$, and pressures greater than $0.1 \mathrm{MPa}$ and up to $10 \mathrm{MPa}$ was measured using a static volumetric technique with a specially designed Sievert's apparatus. The apparatus was previously tested to prove to be leak-free and accurate through calibration by using $\mathrm{LaNi}_{5}, \mathrm{AX}-21$, zeolites, and MOFs at $298 \mathrm{~K}$. Approximately $200 \mathrm{mg}$ of sample was used for each high-pressure isotherm measurement in this study. Before measurements, the samples were degassed in vacuo at $350^{\circ} \mathrm{C}$ for at least $12 \mathrm{~h}$. The storage data under our experimental conditions refer to excess hydrogen uptake.

\section{Molecular Orbital Calculation}

To understand the hydrogen adsorption on the B- and Ndoped microporous carbon via spillover, ab initio molecular orbital calculations were performed for the binding energies between the spiltover hydrogen atom and various sites on the doped microporous carbon.

The Gaussian 03 package $^{39}$ and Cerius 2 molecular modeling software ${ }^{40}$ were used for all molecular orbital (MO) calculations. Density functional theory (DFT) calculations were performed with $\mathrm{p}$ function added in the basis set, thus, B3LYP/6-31 g (d,p) was used for geometry optimization, self-consistent field energy ( $\mathrm{SCF}$ ), and single-point energy (SPE) calculations. The molecular structure selected for the graphite models used in this study consisted of 14 aromatic rings in one single layer as shown in Figure 1. For boron and/or nitrogen doped graphite models, one or two carbons on the center basal sites were replaced by boron(s) or nitrogen(s), or both boron and nitrogen. The chemisorption of hydrogen atom(s) on unsubstituted graphite, and various doped graphite models were calculated from the following expression

$$
\mathrm{E}_{\mathrm{ads}}=\mathrm{E}_{\text {graphite-hydrogen }}-\mathrm{E}_{\text {graphite }}-\mathrm{E}_{\text {hydrogen }}
$$

where $E_{\text {ads }}$ is the energy of chemisorption, $E_{\text {graphite-hydrogen }}$ is the SCF energy of the optimized structure of hydrogen on graphite, $\mathrm{E}_{\text {graphite }}$ is the SCF energy of the optimized structure of the corresponding grapite, and $\mathrm{E}_{\text {hydrogen }}$ is the SCF energy of hydrogen atom.

To determine the potential energy curves for the interaction between $\mathrm{H}$ atom(s) and graphite models, SPE was calculated on each change of the carbon-hydrogen bond length, the resulting SPEs were converted to electron volts per hydrogen $(\mathrm{eV} / \mathrm{H})$ as shown in Figure 2. Basis set superposition error (BSSE) has been neglected.

\section{Results and Discussion}

\section{$B$ - and $N$-doped microporous carbon}

$X R D$. Powder X-ray diffraction patterns of microporous carbon and $\mathrm{B}$ - and $\mathrm{N}$-doped microporous carbon samples are shown in Figure 3. The microporous carbon (Figure 3a) showed a strong peak at $2 \theta=6.3^{\circ}$, indicating that the 


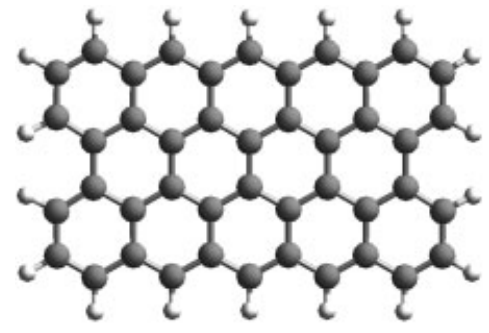

a. un-substituted graphite

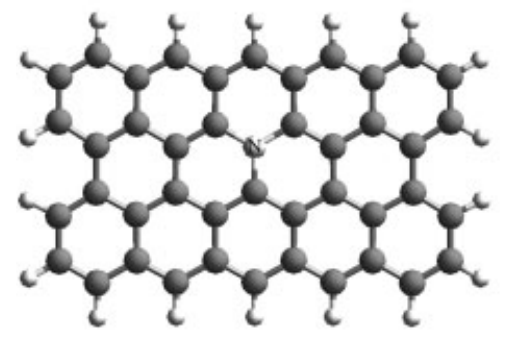

c. graphite with 1 nitrogen

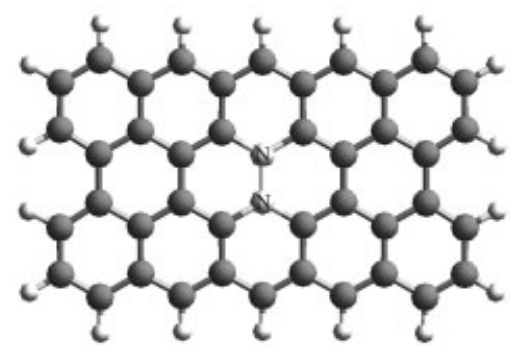

e. graphite with 2 nitrogens

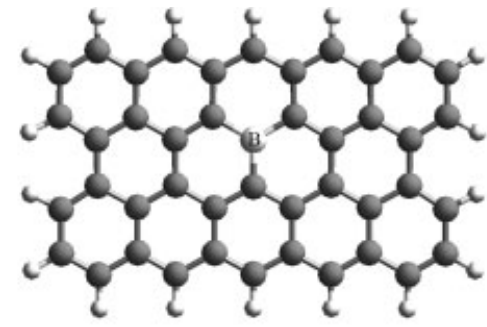

b. graphite with 1 boron

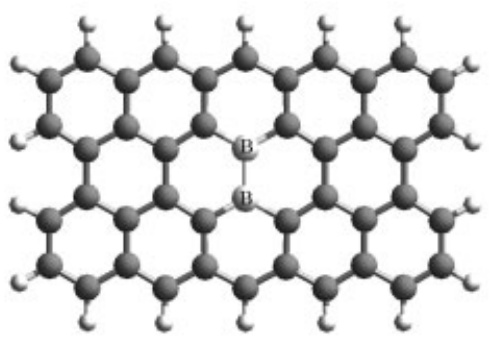

d. graphite with 2 borons

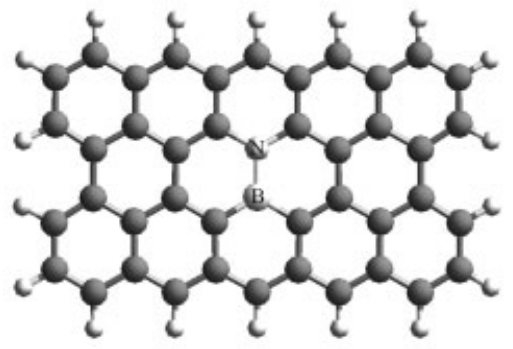

f. graphite with 1 nitrogen $\& 1$ boron

Figure 1. Geometry optimized structures of various graphite models.

ordered structure of zeolite template had been replicated in the carbon. After the substitution treatment, the peak at $2 \theta$ $=6.3^{\circ}$ disappeared in the low-angle XRD pattern of the Band $\mathrm{N}$-doped microporous carbon, indicating that the ordered structure of B- and N-doped microporous carbon had been destroyed during the high temperature treatment (Figure $3 b$ ). It is worth noticing that the wide-angle XRD pattern of Band $\mathrm{N}$-doped microporous carbon exhibited two peaks at $2 \theta$ $=26.3^{\circ}$ and $43.5^{\circ}$, assigned to (002) and (101) diffractions, respectively, of graphite-like structure. This indicates the graphite-like structure was formed in the B- and $\mathrm{N}$-doped microporous carbon during the high-temperature treatment.

Nitrogen Isotherms. Nitrogen isotherms are shown in Figure 4. The isotherms for microporous carbon and B- and $\mathrm{N}$-doped microporous carbon samples both exhibited the typical Type I isotherm, indicating the presence of microporosity in these two samples. The BET surface area and pore volume of the microporous carbon were $3771 \mathrm{~m}^{2} / \mathrm{g}$ and 1.83 $\mathrm{cm}^{3} / \mathrm{g}$, respectively. These textural properties were comparable to those of reported zeolite templated carbon with highsurface areas. ${ }^{4,8}$ After the substitution reaction, the BET surface area and pore volume of $\mathrm{B}$ - and $\mathrm{N}$-doped microporous carbon were $1215 \mathrm{~m}^{2} / \mathrm{g}$ and $0.62 \mathrm{~cm}^{3} / \mathrm{g}$, respectively, which were much lower compared to the microporous carbon tem- plate. This is mainly attributed to the partial porosity collapse during the substitution reaction at high-temperature, in agreement with the XRD results. However, it is encouraging

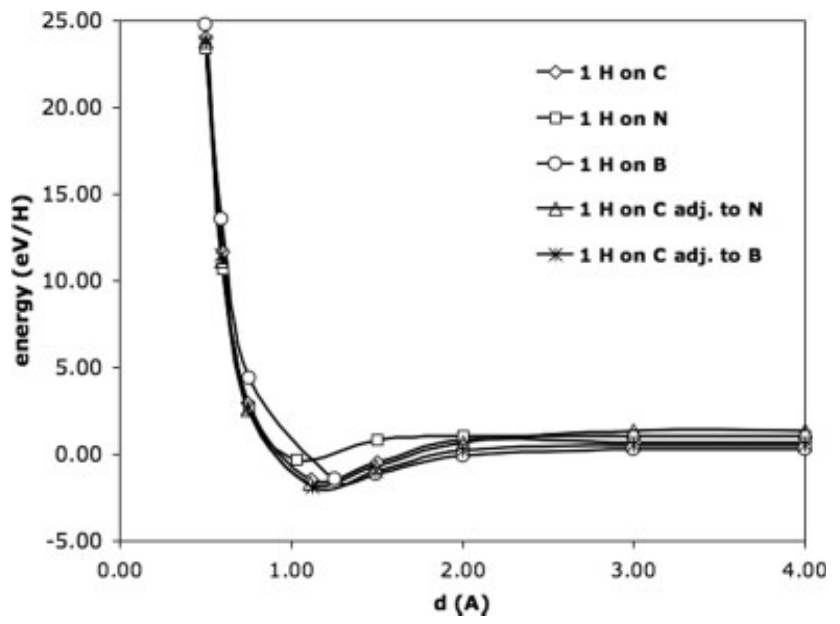

Figure 2. Potential energy diagram for an atomic hydrogen on various graphite models $(1 \mathrm{eV}=$ $\left.1.602 \times 10^{-19} \mathrm{~J}\right)$. 

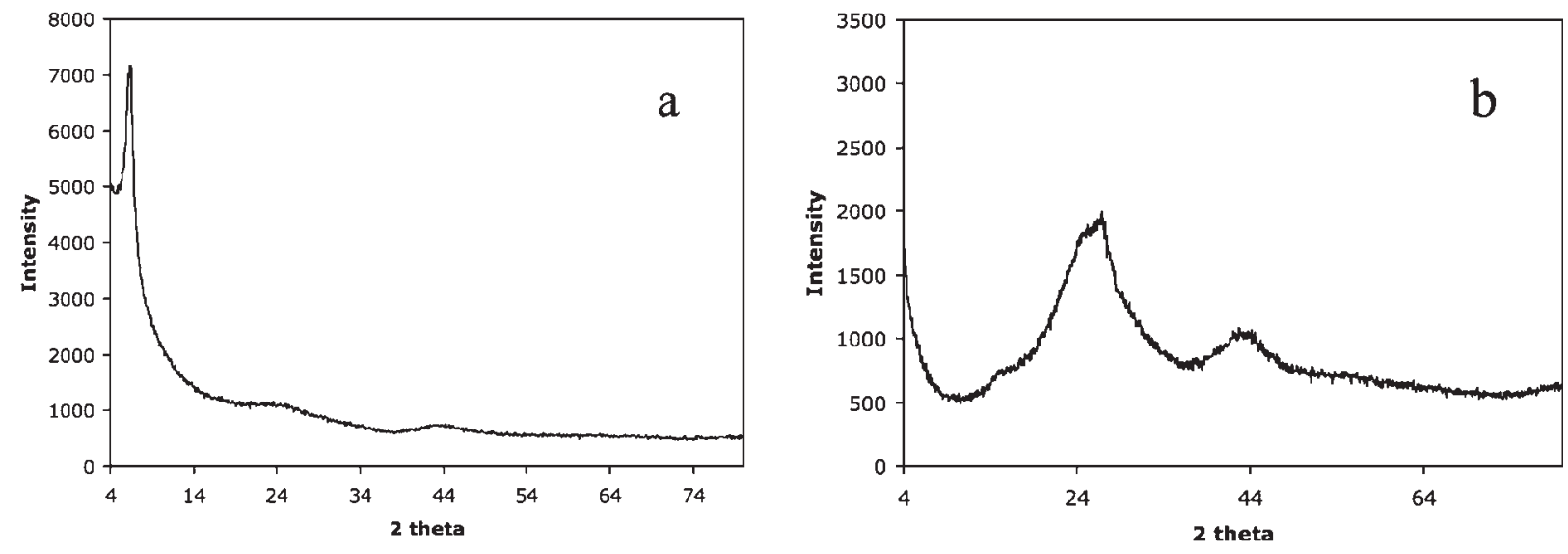

Figure 3. (a) X-ray diffraction patterns of microporous carbon (a), B- and N-doped microporous carbon (b).

that the surface area of the B- and N-doped microporous carbon was much higher than all previously reported high surface area mesoporous $\mathrm{BCN}\left(740 \mathrm{~m}^{2} / \mathrm{g}\right),{ }^{38} \mathrm{~B}$ - and $\mathrm{N}$-doped amorphous carbon $\left(188 \mathrm{~m}^{2} / \mathrm{g}\right),{ }^{36} \mathrm{BCN}$ nanotubes $\left(356 \mathrm{~m}^{2} /\right.$ $\mathrm{g}),{ }^{31}$ and activated $\mathrm{BN}\left(168 \mathrm{~m}^{2} / \mathrm{g}\right),{ }^{41}$ indicating that the use of microporous carbon is helpful for synthesizing high-surface area B- and N-doped microporous carbon.

TEM. High-resolution TEM images of the microporous carbon and the B- and N-doped microporous carbon samples are shown in Figure 5. As shown in Figure 5a, microporous carbon exhibited highly ordered microporous channels, confirming the successful structural transfer from the zeolite template. Although for the B- and N-doped microporous carbon (Figure 5b), it is difficult to observe ordered microporous channels. It is noted that the graphite-like structures could be clearly observed at the edges of the B- and Ndoped microporous carbon sample. This indicates that the ordered microstructure collapsed and graphitized during the substitution reaction at high temperature. These results are in agreement with the XRD and nitrogen observations.

EELS. Electron energy-loss spectrum (EELS) of the Band $\mathrm{N}$-doped microporous carbon clearly showed the presence of the K-shell excitation of carbon, boron, nitrogen and oxygen (Figure 6). Sharp $\pi^{*}$-peaks (lefthand sides of the B and $\mathrm{N} \mathrm{K}$-shell excitation edges), and the shape of $\sigma ; *$-bands

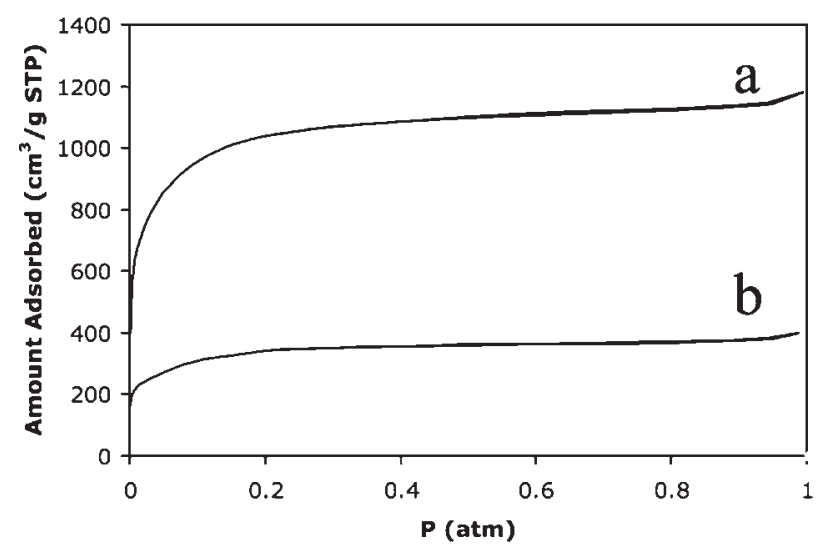

Figure 4. Nitrogen isotherms of microporous carbon (a), B- and N-doped microporous carbon (b). (righthand sides of the edges) are characteristics of $\mathrm{B}$ and $\mathrm{N}$ atoms in the graphite-like $\mathrm{sp}^{2}$ bonded network, indicating that $\mathrm{B}$ and $\mathrm{N}$ atoms have been substituted into the graphitic
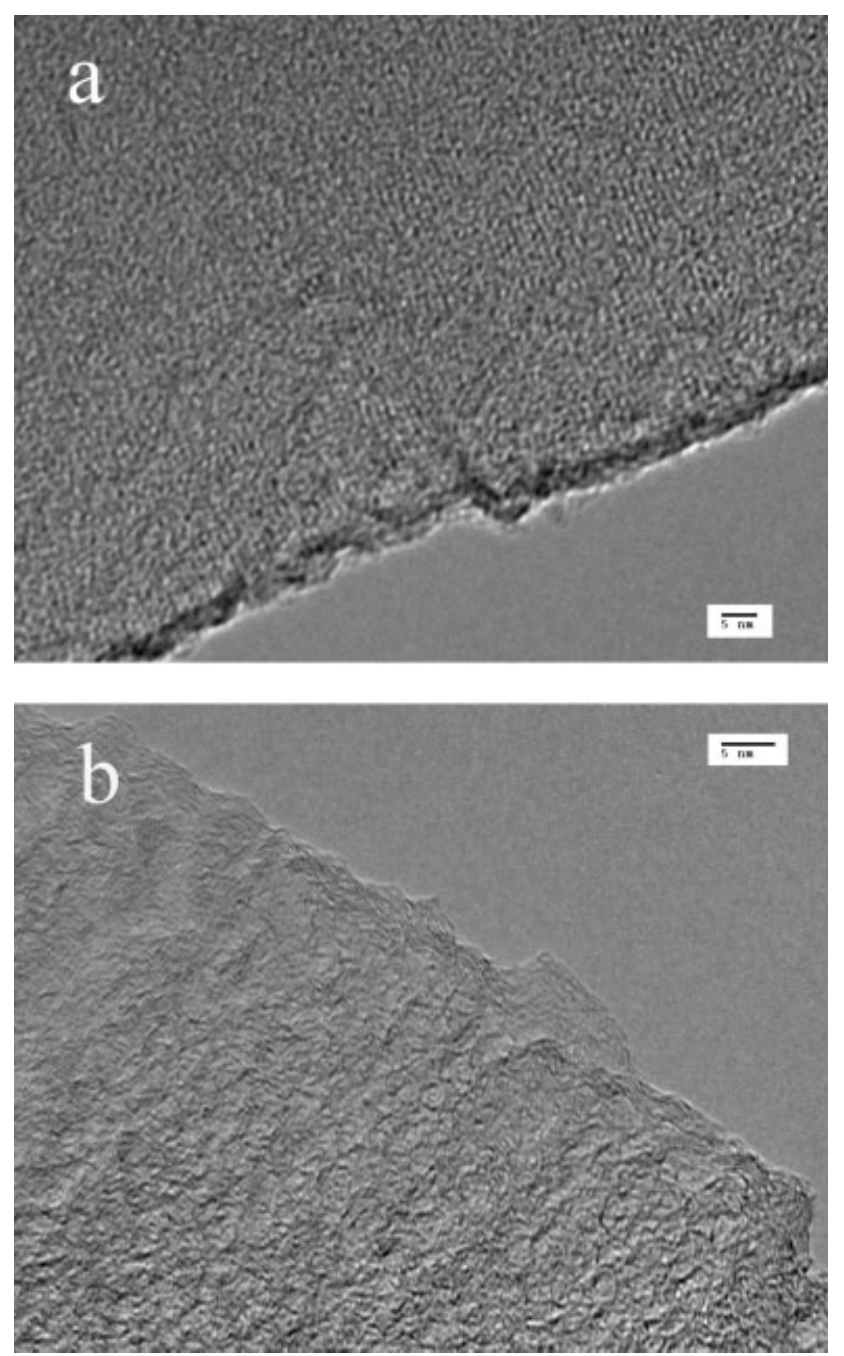

Figure 5. TEM images of microporous carbon (a), Band $\mathrm{N}$-doped microporous carbon (b), scale bar: $5 \mathrm{~nm}$. 


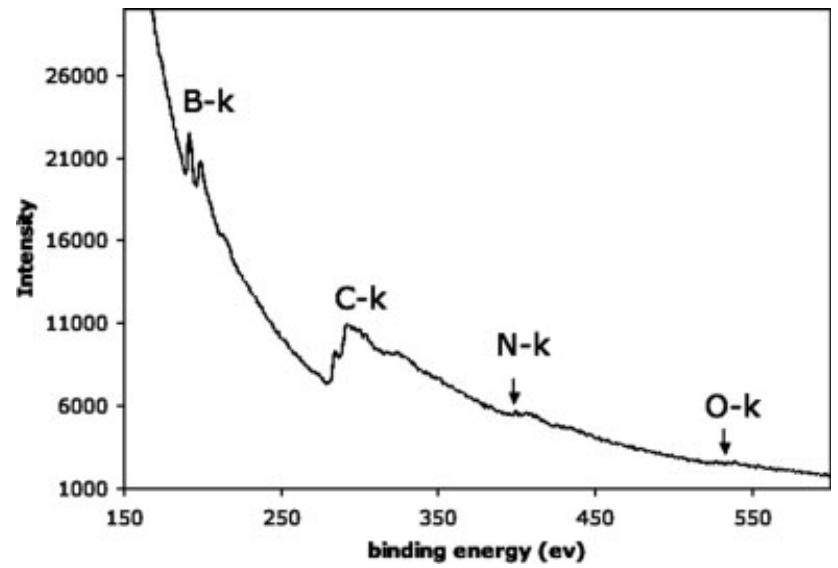

Figure 6. EELS spectrum of B- and N-doped microporous carbon.

rings in the framework of B- and N-doped microporous carbon. This result is in agreement with the observed graphitelike structure of the $\mathrm{B}$ - and $\mathrm{N}$-doped microporous carbon from the XRD and TEM results.

$X P S$. The X-ray Photoelectron survey spectrum (Figure 7) of B- and N-doped microporous carbon showed four sharp signals for $\mathrm{B}, \mathrm{N}, \mathrm{C}$ and $\mathrm{O}$ elements, in agreement with the EELS results. The elemental composition of the $\mathrm{B}-$ and $\mathrm{N}$ doped microporous carbon was approximately $\mathrm{B}_{9} \mathrm{C}_{64} \mathrm{~N}_{10} \mathrm{O}_{17}$, indicating that using the microporous carbon as a template was efficient for the substitution reaction.

SEM. SEM images of the microporous carbon and the B- and N-doped microporous carbon samples are shown in Figure 8 . The microporous carbon consisted of pure hexagonal platelets, in good agreement with the typical morphology of EMC-2 zeolite. This also confirms that the structure of the original zeolite has been successfully transferred into the microporous carbon. The B- and N-doped microporous carbon showed the same morphology as that of the microporous carbon. This indicates that the morphology of microporous carbon has been retained during the substitution treatment. No other morphology than hexagonal platelets could be

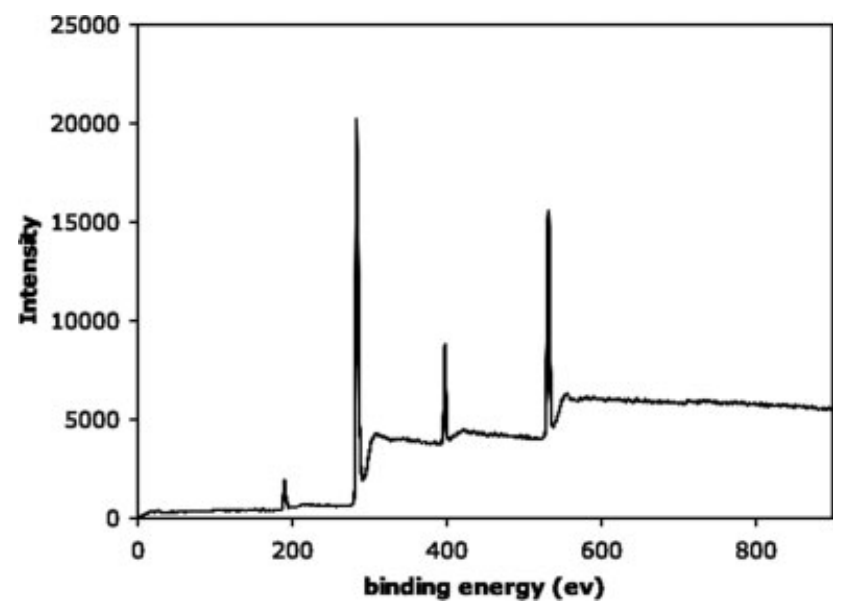

Figure 7. XPS spectrum of B- and N-doped microporous carbon.
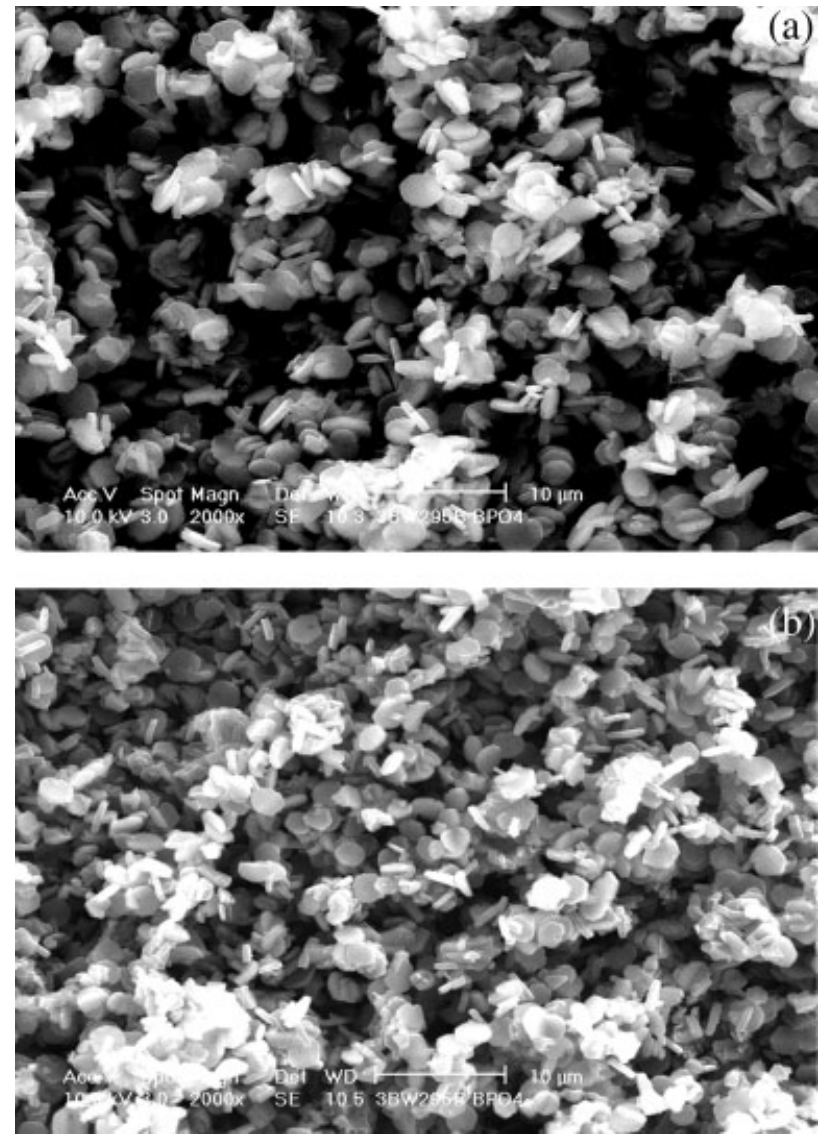

Figure 8. SEM images of microporous carbon (a), Band $\mathrm{N}$-doped microporous carbon (b).

observed on the B- and N-doped microporous carbon, indicating the purity in the obtained samples.

Hydrogen Isotherms. High-pressure hydrogen isotherms at $298 \mathrm{~K}$ for the $\mathrm{B}$ - and $\mathrm{N}$-doped microporous carbon are presented in Figure 9. As shown in Figure 9, the B- and Ndoped microporous carbon had a hydrogen storage capacity of $0.55 \mathrm{wt} \%$ at $298 \mathrm{~K}$ and $10 \mathrm{MPa}$. In comparison, a porous

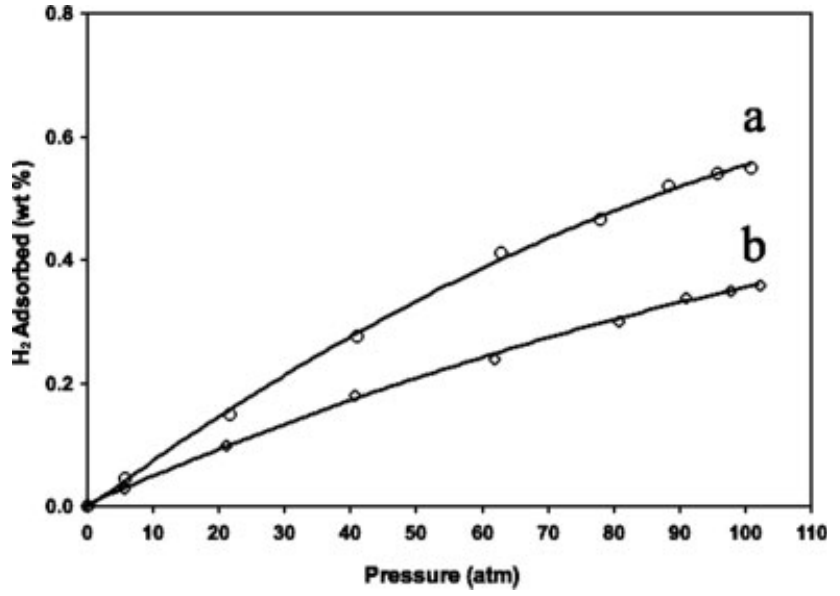

Figure 9. High-pressure hydrogen isotherms at $298 \mathrm{~K}$ for B- and N-doped microporous carbon (a: $\bigcirc$ ) and porous carbon CMK-3 (b: $\diamond)$. 
Table 1. Stability Comparison Between B and N Substituted Graphite Models

\begin{tabular}{lcc}
\hline \multicolumn{1}{c}{ Graphite models } & $\begin{array}{c}\text { SCF } \\
\text { Energy } \\
(\mathrm{Kcal} / \mathrm{mol})\end{array}$ & $\begin{array}{c}\% \text { difference } \\
\text { in stability }\end{array}$ \\
\hline A-unsubstituted & -1059064.23 & \\
B-substituted with 1 boron & -1050742.55 & -0.79 \\
C-substituted with 1 nitrogen & -1069494.67 & +0.98 \\
D-substituted with 2 adjacent borons & -1042378.95 & -1.63 \\
E-substituted with 2 adjacent nitrogens & -1079885.15 & +1.93 \\
F-substituted with 1 boron \& 1 nitrogen & -1061201.63 & +0.20 \\
\hline
\end{tabular}

pure carbon CMK-3 with a BET surface area of $1260 \mathrm{~m}^{2} / \mathrm{g}$ had a storage capacity of $0.36 \mathrm{wt} \%$ under the same conditions (Supporting Table 1). Obviously, the hydrogen uptake on the B- and N-doped microporous carbon was 53\% higher than the carbonaceous materials with similar surface area. Recently, Chung et al. also observed an enhanced hydrogen uptake of 0.4 wt $\%$ on a boron substituted carbon with a BET surface area of $780 \mathrm{~m}^{2} / \mathrm{g}$ at ambient temperature and $>60$ bar. $^{42}$ Compared with their carbon, the B- and N-doped microporous carbon in this work showed a larger BET surface area $\left(1215 \mathrm{~m}^{2} / \mathrm{g}\right)$, and a higher storage capacity for hydrogen.

The heats of adsorption of $\mathrm{H}_{2}$ on the $\mathrm{B}$ - and $\mathrm{N}$-doped microporous carbon were calculated from the $\mathrm{H}_{2}$ adsorption isotherms at $273 \mathrm{~K}$ and $298 \mathrm{~K}$ by using the Clausius-Clapeyron equation, as shown in Figure 10. The isosteric heats of adsorption were determined by evaluating the slope of the plot of $\ln (\mathrm{P})$ vs. $(1 / \mathrm{T})$ at the same adsorption amount. It can be seen that the $\mathrm{H}_{2}$ adsorption amounts at all pressures up to $1 \mathrm{~atm}$ decreased with an increase in temperature. Figure 10 inset showed that the absolute values of the heat of adsorption decreased with adsorption amount for the B- and Ndoped microporous carbon. The heats of adsorption was $\sim 14$ $\mathrm{kJ} / \mathrm{mol}$ at low-surface coverage, and leveled off to $\sim 10 \mathrm{~kJ} /$ mol at relatively high-surface coverage. The high values of heats of adsorption at low-surface coverage can be attributed to the adsorption of $\mathrm{H}_{2}$ on the more energetic sites on carbon. Defect sites, edge sites (i.e., armchair and zigzag edge

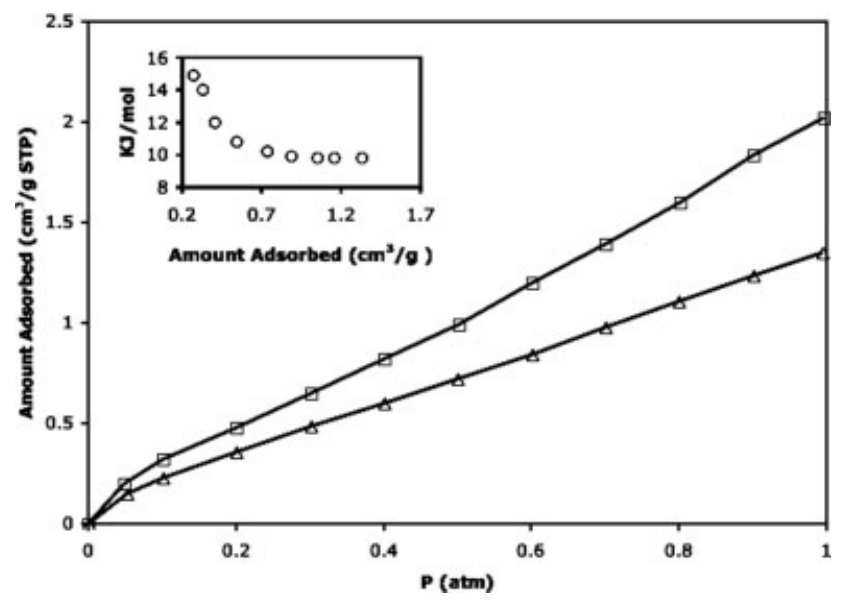

Figure 10. Low-pressure $\mathrm{H}_{2}$ adsorption isotherms for B- and N-doped microporous carbon at 273 $\mathrm{K}(\square)$, and $298 \mathrm{~K}(\triangle)$; Inset: Calculated isosteric heats of adsorption: $-\Delta H(\bigcirc)$. sites of graphite crystallites), and surface oxygen complexes are strong sites for adsorption. The heats of adsorption $(\sim 10$ $\mathrm{kJ} / \mathrm{mol}$ ) at high $\mathrm{H}_{2}$ adsorption amount on the $\mathrm{B}$ - and $\mathrm{N}$ doped microporous carbon were still higher than that on pure carbon $(\sim 6 \mathrm{~kJ} / \mathrm{mol}){ }^{43}$ The relative high-heat of adsorption on $\mathrm{B}$ - and $\mathrm{N}$-doped microporous carbon suggests more $\mathrm{H}_{2}$ favorably bonded to $\mathrm{B}$ - and $\mathrm{N}$-doped microporous carbon. The higher heats of adsorption on heteroatom substituted carbon than pure carbon have been also reported by other authors. ${ }^{42,44}$

\section{$R u / B$ - and $N$-doped microporous carbon}

Hydrogen storage is the crucially missing link to a future "hydrogen economy." 45 Our recent studies showed that the hydrogen storage capacities at $298 \mathrm{~K}$ in nanostructured and porous materials including carbon, zeolites and metal-organic frameworks could be enhanced significantly by exploiting the hydrogen spillover phenomenon. ${ }^{46-52}$ Hydrogen spillover is defined as the dissociative chemisorption of hydrogen on metal nanoparticles, and subsequent migration of hydrogen atoms onto adjacent surfaces of a receptor via spillover or surface diffusion. ${ }^{53-55}$ Hydrogen storage on various carbon materials (CNTs, active carbon, carbon nanofibers, etc) doped with metals have been studied. ${ }^{56-62}$ However, there is no study on hydrogen spillover-storage on boron- and nitrogen-doped carbon. Enhanced hydrogen storage capacity has been obtained on B- and $\mathrm{N}$-doped microporous carbon in this work, and it is expected that doping of Ru metal on the $\mathrm{B}$ - and $\mathrm{N}$-doped microporous carbon would further enhance the storage capacity due to hydrogen spillover. Thus, we synthesized $\mathrm{Ru} / \mathrm{B}$ - and $\mathrm{N}$-doped microporous carbon and investigated its hydrogen storage properties.

$X R D$. After doping $\mathrm{Ru}$ on the $\mathrm{B}$ - and N-doped microporous carbon, the wide-angle XRD pattern (Figure 11) of Ru/ $\mathrm{B}$ - and $\mathrm{N}$-doped microporous carbon showed typical peaks at

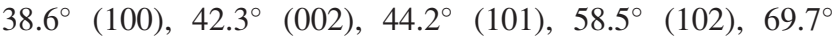
(110) and $78.6^{\circ}$ (103) characteristic of the metallic ruthenium (ICDD-JCPDS Card No. 06-0663). The particle sizes of $\mathrm{Ru}$ calculated from Scherrer equation were approximately $10 \mathrm{~nm}$. These results confirm that nanosized $\mathrm{Ru}$ metals have

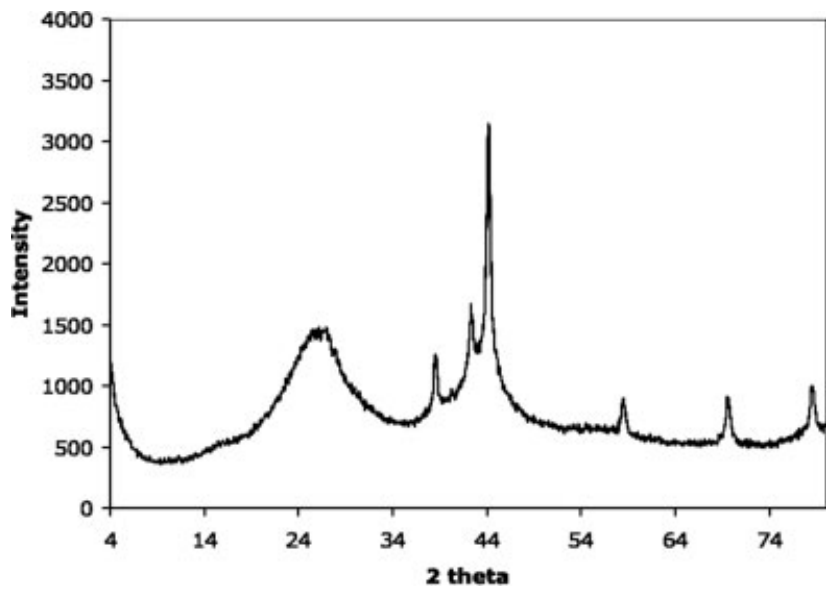

Figure 11. X-ray diffraction pattern of Ru/B- and Ndoped microporous carbon. 


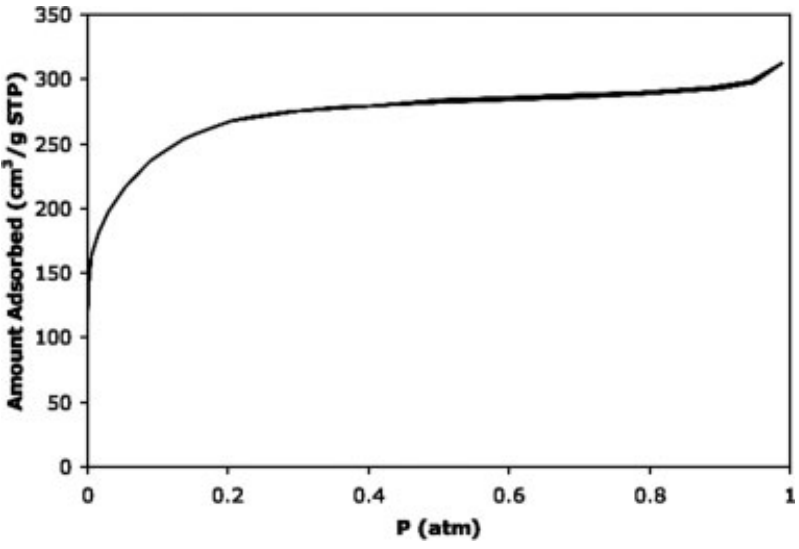

Figure 12. Nitrogen isotherm of Ru/B- and N-doped microporous carbon.

been doped on the B- and $\mathrm{N}$-doped microporous carbon. $\mathrm{Ru} /$ B- and N-doped microporous carbon showed a broad peak around $26.3^{\circ}$, the same as that of B- and N-doped microporous carbon, which corresponds to the (101) diffraction of graphite-like structure.

Nitrogen Isotherm. The nitrogen isotherm (Figure 12) of $\mathrm{Ru} / \mathrm{B}$ - and N-doped microporous carbon showed typical Type I isotherm, indicating the presence of microporosity. The BET surface area and pore volume of the $\mathrm{Ru} / \mathrm{B}$ - and Ndoped microporous carbon were $953 \mathrm{~m}^{2} / \mathrm{g}$ and $0.48 \mathrm{~cm}^{3} / \mathrm{g}$, respectively. The BET surface area and pore volume of the $\mathrm{Ru} / \mathrm{B}$ - and $\mathrm{N}$-doped microporous carbon were lower than that of the B- and N-doped microporous carbon (Supporting Table 1). This was due to the increased weight and micropore blocking caused by $\mathrm{Ru}$ metal particles.

TEM. High-resolution TEM images of $\mathrm{Ru} / \mathrm{B}-$ and $\mathrm{N}$ doped microporous carbon are shown in Figure 13. The nanosized black spots of Ru were well dispersed on the surface of the Ru-B- and N-doped microporous carbon. Particles of $5-10 \mathrm{~nm}$ can be clearly observed. It is noted that $\mathrm{XRD}$ pattern is more sensitive to large particles, thus, the

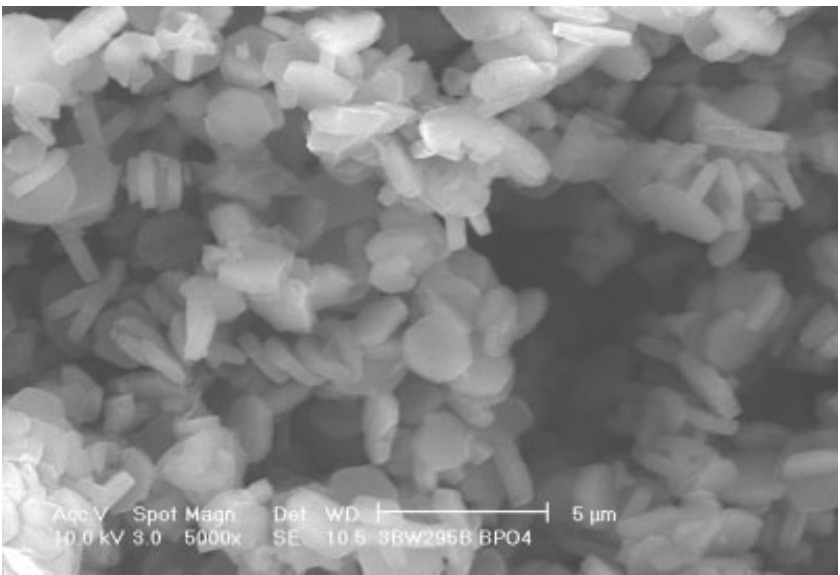

Figure 14. SEM image of Ru/B- and N-doped microporous carbon.

TEM observations were in agreement with the XRD results. These results further confirm that $\mathrm{Ru}$ metals have been successfully doped on the B- and N-doped microporous carbon support.

SEM. SEM image (Figure 14) showed that the Ru/B- and $\mathrm{N}$-doped microporous carbon consisted of the pure hexagonal platelets, the same morphology as that of the microporous carbon and $\mathrm{B}-$ and $\mathrm{N}$-doped microporous carbon. This indicates that the morphology of the B- and N-doped microporous carbon has been retained during the doping treatment. No other morphology than hexagonal platelets can be observed on the $\mathrm{Ru} / \mathrm{B}$ - and $\mathrm{N}$-doped microporous carbon, indicating the purity in the obtained sample.

Hydrogen Isotherms. High-pressure hydrogen isotherms at $298 \mathrm{~K}$ for the B- and $\mathrm{N}$-doped microporous carbon and the $\mathrm{Ru} / \mathrm{B}$ - and $\mathrm{N}$-doped microporous carbon samples are compared in Figure 15. The B- and N-doped microporous carbon had a hydrogen storage capacity of 0.55 wt \% at 298 $\mathrm{K}$ and $10 \mathrm{MPa}$. By doping $6.0 \mathrm{wt} \% \mathrm{Ru}$ metal on the B- and $\mathrm{N}$-doped microporous carbon, the hydrogen uptake at 10

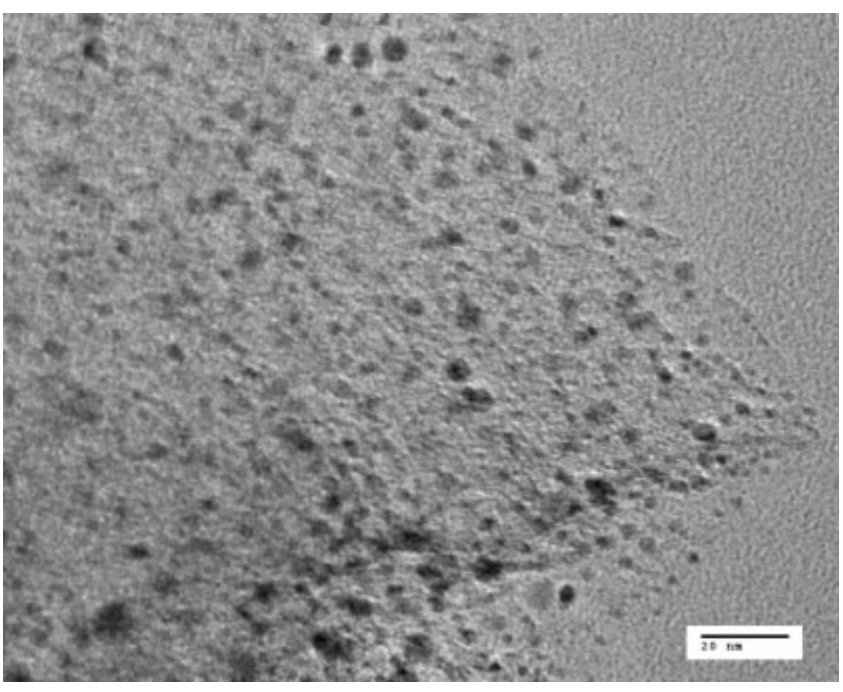

Figure 13. TEM image of Ru/B- and N-doped microporous carbon, scale bar: $20 \mathrm{~nm}$.

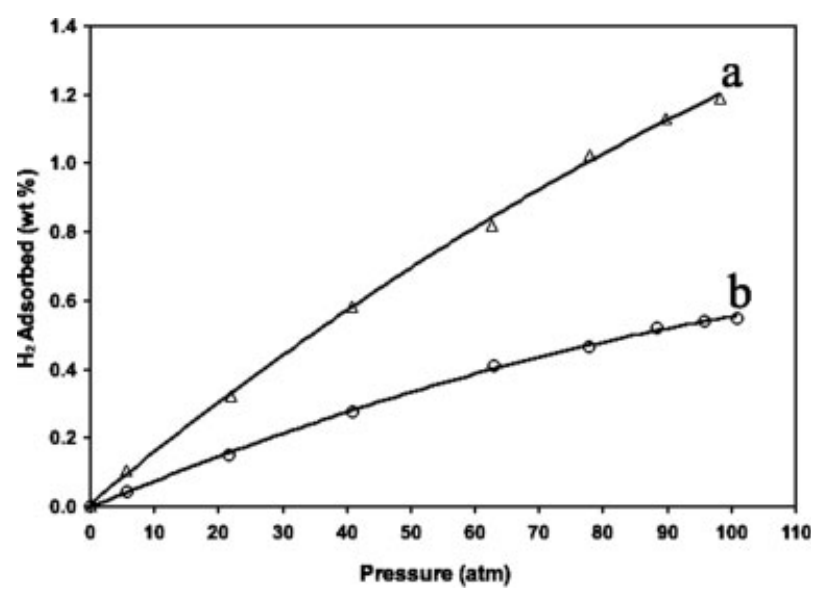

Figure 15. High-pressure hydrogen isotherms at $298 \mathrm{~K}$ on $\mathrm{Ru} / \mathrm{B}-$ and $\mathrm{N}$-doped microporous carbon (a: $\triangle$ ) and $\mathrm{B}$ - and $\mathrm{N}$-doped microporous carbon (b: $\bigcirc$ ). 
MPa was increased to $1.2 \mathrm{wt} \%$, i.e., more than doubled. The enhanced hydrogen storage capacity should not be attributed to any differences in surface area because the $\mathrm{Ru} /$ B- and N-doped microporous carbon had a lower surface area than that of the $\mathrm{B}$ - and $\mathrm{N}$-doped microporous carbon. The enhancement of hydrogen storage was due to the spillover of atomic hydrogen from the Ru metal particles to the $\mathrm{B}-$ and N-doped microporous carbon. $\mathrm{Ru}, \mathrm{Pt}, \mathrm{Ni}$ and Pd metals are all effective as hydrogen dissociation sources, and the enhanced hydrogen storage by metal doped on pure carbon materials (CNTs, active carbon, carbon nanofiber, etc.) have been reported. ${ }^{56-62}$ In our case, in comparison with the Band $\mathrm{N}$-doped microporous carbon, it is remarkable that the hydrogen adsorption amount of the $\mathrm{Ru} / \mathrm{B}$ - and $\mathrm{N}$-doped microporous carbon has been enhanced by a factor of 2.2. Furthermore, reversibility on $\mathrm{Ru} / \mathrm{B}$ - and N-doped microporous carbon was evaluated by measuring the desorption branch down to $1 \mathrm{~atm}$. It can be seen from supporting Figure 1 that the desorption branch nearly followed the adsorption branch, although there appeared to be a slight hysteresis. The sample was then evacuated to a pressure of $1 \mathrm{~Pa}$ for 12 $\mathrm{h}$ at $298 \mathrm{~K}$ and total desorption occurred. The second adsorption isotherm was in agreement with the first adsorption isotherm, indicating reversible adsorption.

The heats of adsorption of $\mathrm{H}_{2}$ on the $\mathrm{Ru} / \mathrm{B}$ - and N-doped microporous carbon were calculated from the $\mathrm{H}_{2}$ adsorption isotherms at $273 \mathrm{~K}$ and $298 \mathrm{~K}$ by using the Clausius-Clapeyron equation. As shown in Figure 16, the heats of adsorption were $>20 \mathrm{KJ} / \mathrm{mol}$ at low-surface coverage and leveled off to $\sim 15 \mathrm{~kJ} / \mathrm{mol}$ at relatively high-surface coverage. The high values of heats of adsorption at low-surface coverage can be attributed to the strong adsorption of $\mathrm{H}$ atoms on the $\mathrm{Ru}$ particles, as well as the $\mathrm{H}$ atoms on the strongest sites on carbon. It has been reported that atomic hydrogen can be strongly adsorbed at defect sites on carbon materials and some defects can be generated during the catalyst preparation. ${ }^{63-65}$

It is known that the Clausius-Clapeyron equation yields the overall heats of adsorption. In this case, the heats of adsorption are approximately the overall values of the bonding energies of $\mathrm{H}_{2}$ on carbon, $\mathrm{H}$ atoms on metal and various carbon sites. As a first-order analysis, we take the heat of adsorption at high $\mathrm{H}_{2}$ adsorption amount as an indicator of the adsorption strength of hydrogen atoms on the surface of the $\mathrm{Ru} / \mathrm{B}$ - and $\mathrm{N}$-doped microporous carbon. The heat of adsorption at high $\mathrm{H}_{2}$ adsorption amount on the $\mathrm{Ru} / \mathrm{B}$ - and $\mathrm{N}$-doped microporous carbon sample is about $15 \mathrm{~kJ} / \mathrm{mol}$. The relative higher heat of adsorption on $\mathrm{Ru} / \mathrm{B}$ - and $\mathrm{N}$-doped microporous carbon than on $\mathrm{B}$ - and $\mathrm{N}$-doped microporous carbon suggests more $\mathrm{H}$ atoms were favorably bonded to $\mathrm{Ru} / \mathrm{B}$ - and $\mathrm{N}$-doped microporous carbon, in agreement with the high-pressure results. It is noted that the heat of adsorption on $\mathrm{Ru} / \mathrm{B}$ - and $\mathrm{N}$-doped microporous carbon is also higher than $\mathrm{Ru}$ on pure carbons $(11 \mathrm{KJ} / \mathrm{mol}){ }^{62}$ This indicates that $\mathrm{B}$ and $\mathrm{N}$ doping is more favorable for hydrogen adsorption via spillover than that on pure carbons. From our experimental results, hydrogen storage capacity on $\mathrm{B}-$ and $\mathrm{N}$ doped carbon can be significantly enhanced via spillover. However, it is still not clear that which sites on the doped carbon are more favorable for adsorption of spiltover $\mathrm{H}$ atoms. Understanding the contributions of various sites on

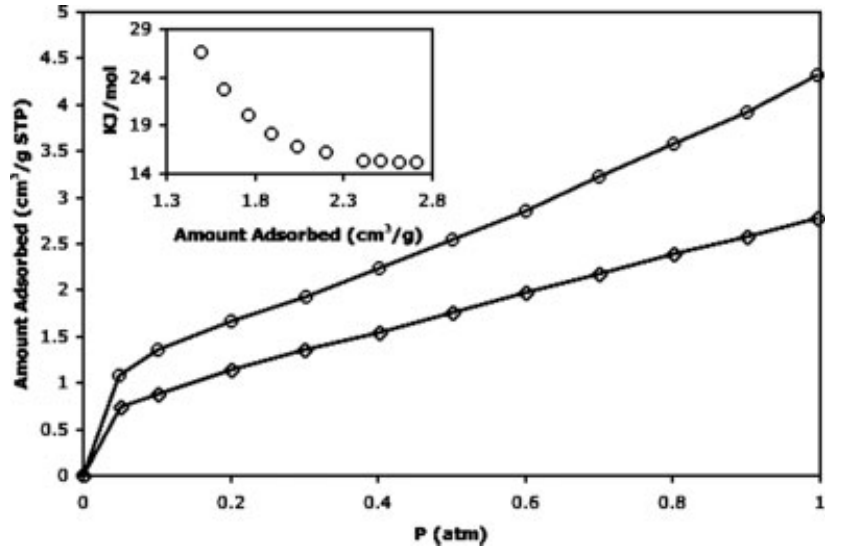

Figure 16. Low-pressure $\mathrm{H}_{2}$ adsorption isotherms for Ru/B- and N-doped microporous carbon at $273 \mathrm{~K}(\bigcirc)$, and $298 \mathrm{~K}(\diamond)$; Inset: Calculated isosteric heats of adsorption: $-\Delta \mathbf{H}(\bigcirc)$.

doped carbon will be helpful for further design of promising adsorbents for hydrogen storage. Thus, the $\mathrm{B}$ and $\mathrm{N}$ doping effect on hydrogen adsorption is further discussed in the following molecular orbital calculation results.

\section{Molecular orbital calculations}

It is known that hydrogen spillover involves a number of complex steps: dissociation on the metal, migration of $\mathrm{H}$ from metal to carbon, migration on carbon, recombination on carbon, and binding on carbon sites. However, complete simulation of the spillover process has not been done; simulations of some of the aforementioned steps have provided insights into the spillover process. ${ }^{66}$ Meantime, much evidence has been reported in the literature on the existence of $\mathrm{H}$ atoms that are involved in the spillover process. ${ }^{55}$ Recent examples include direct observation using inelastic neutron scattering studies ${ }^{67,68}$ which have provided evidence of atomic hydrogen spillover from Pt to carbon at room-temperature. The calculation results for $\mathrm{H}$ atoms binding on different graphene sites only represent the last step of the spillover process. Without a complete simulation of the spillover process, it is not possible to directly relate the binding energy from the calculation and the overall heats of adsorption that are obtained from the temperature dependence of the isotherms. However, it is clear that they are related; i.e., a stronger binding energy leads to a higher overall heat of adsorption. Thus, the calculation results should provide an indication whether boron and nitrogen doping will lead to higher heats of adsorption, or more favorable adsorption.

Theoretical calculations of hydrogen atoms on boron and nitrogen doped carbon materials have been reported by several authors, ${ }^{44,69-72}$ some of these studies also dealt with molecular hydrogen interaction on carbon materials. In case of chemisorption of hydrogen atom on boron- and nitrogendoped carbon materials, the interaction of hydrogen atom on carbon materials substituted with both boron and nitrogen on the same graphite structure has not been reported.

Because it has been reported that graphite models containing less than 13 aromatic rings may result in incorrect result from their MO calculations, ${ }^{44}$ in this study, we selected a 
Table 2. Bond Length $(\AA)$ in Geometry Optimized Graphite Models

\begin{tabular}{lcc}
\hline \multicolumn{1}{c}{ Graphite models } & $\begin{array}{c}\text { Bond } \\
\text { length }(\AA)\end{array}$ & $\begin{array}{c}\text { Reported }^{44} \\
\text { for } \\
\text { graphene }\end{array}$ \\
\hline A-unsubstituted & C-C : 1.421 & 1.422 \\
B-substituted with 1 boron & B-C : 1.492 & 1.487 \\
C-substituted with 1 nitrogen & N-C : 1.415 & 1.419 \\
D-substituted with 2 adjacent borons & B-C : 1.499 & \\
E-substituted with 2 adjacent nitrogens & N-C : 1.410 & \\
F-substituted with 1 boron \& 1 nitrogen & N-C : 1.410 & \\
\hline
\end{tabular}

graphite model with 14 aromatic rings in the molecular structure. The central one or two carbon atoms were substituted for a boron or/and a nitrogen atoms, thus, resulting in various boron and nitrogen substituted graphite models, their geometry optimized structures are shown in Figure 1. The optimized structure of the graphite remained as a flat sheet after substitutions, but became slightly curved after hydrogen adsorption in all graphite models.

The result of our MO calculations indicated that boron substitution destabilized the graphite structure, which was also observed by Zhu et al. ${ }^{44}$ However, the opposite was true for nitrogen substitution, which stabilized the graphite structure as shown in Table 1. This may be explained by the difference in valence electrons. Boron has one less valence electron than carbon, it does not form resonance structure with its three neighboring carbons, therefore, boron-carbon bond length is slightly longer than the unsubstituted carboncarbon bond, whereas nitrogen has one more valence electron than carbon, it can still form resonance structure with its neighboring carbons, so nitrogen-carbon bond length is slightly shorter, as shown in Table 2 . When the graphite structure was substituted with both 1 boron and 1 nitrogen at the same time, then the structure was found to be still slightly stabilized.

When hydrogen is chemisorbed on the center carbon of the unsubstituted graphite, the $\mathrm{C}-\mathrm{C}$ bond length of the active carbon to the neighboring three carbons is increased to 1.51 $\AA$, this is due a change of $\mathrm{C}-\mathrm{C}$ resonance bond to $\mathrm{C}-\mathrm{C}$ single bond. In case of substituted graphite models, B-C bond is

Table 3. Bond Length $(\AA)$ in Geometry Optimized Graphite Models with Chemisorption of Hydrogen(s)

\begin{tabular}{|c|c|c|}
\hline Graphite models & $\begin{array}{c}\text { Bond } \\
\text { length }(\AA)\end{array}$ & $\begin{array}{c}\text { Reported }^{71} \\
\text { for }(8,0) \text { carbon } \\
\text { nanotubes }\end{array}$ \\
\hline $\begin{array}{l}\text { A-unsubstituted with } 1 \text { hydrogen } \\
\text { on carbon }\end{array}$ & $\begin{array}{l}\text { C-C }: 1.510 \\
\text { C-H }: 1.116\end{array}$ & 1.509 \\
\hline B-with 1 hydrogen on boron & $\begin{array}{l}\text { B-C }: 1.533 \\
\text { B-H : } 1.250\end{array}$ & 1.573 \\
\hline $\mathrm{C}$-with 1 hydrogen on nitrogen & $\begin{array}{l}\mathrm{N}-\mathrm{C}: 1.511 \\
\mathrm{~N}-\mathrm{H}: 1.036\end{array}$ & 1.506 \\
\hline D-with 2 hydrogens on 2 borons & $\begin{array}{l}\text { B-C }: 1.545 \\
\text { B-H : } 1.228\end{array}$ & \\
\hline E-with 2 hydrogens on 2 nitrogens & $\begin{array}{l}\mathrm{N}-\mathrm{C}: 1.514 \\
\mathrm{~N}-\mathrm{H}: 1.045\end{array}$ & \\
\hline $\begin{array}{l}\text { F-with } 1 \text { hydrogen on } 1 \text { boron, and } \\
1 \text { hydrogen on } 1 \text { nitrogen }\end{array}$ & $\begin{array}{l}\text { B-C }: 1.575 \\
\text { B-H }: 1.224 \\
\text { N-C }: 1.496 \\
\text { N-H : } 1.023\end{array}$ & \\
\hline
\end{tabular}

Table 4. Calculated Eads for Chemisorption of 1 Hydrogen $($ Kcal $=4.184 \mathrm{KJ})$

\begin{tabular}{|c|c|c|}
\hline Graphite models & $\begin{array}{c}E_{\mathrm{ads}} \\
(\mathrm{Kcal} / \mathrm{mol})\end{array}$ & $\begin{array}{c}\text { Reported }^{71} \\
\text { for }(8,0) \\
\text { carbon } \\
\text { nanotubes }\end{array}$ \\
\hline A-unsubstituted with 1 hydrogen on carbon & -33.77 & -46.7 \\
\hline B-with 1 hydrogen on boron & -34.01 & -49.8 \\
\hline B-with 1 hydrogen on carbon adj. to boron & -43.73 & \\
\hline C-with 1 hydrogen on nitrogen & -6.32 & -28.4 \\
\hline C-with 1 hydrogen on carbon adj. nitrogen & -38.34 & \\
\hline
\end{tabular}

longer than $\mathrm{C}-\mathrm{C}$ bond, and $\mathrm{N}-\mathrm{C}$ bond is close to the $\mathrm{C}-\mathrm{C}$ bond for a single nitrogen substitution. In case of substitution with one nitrogen and one boron, the $\mathrm{N}-\mathrm{C}$ bond is the shortest, i.e., $1.496 \AA$ and the $\mathrm{B}-\mathrm{C}$ bond is the longest, i.e., $1.575 \AA$, thus, $\mathrm{B}-\mathrm{C}>\mathrm{C}-\mathrm{C}>\mathrm{N}-\mathrm{C}$, this same trend is observed for the corresponding hydrogen bonds, i.e., B-H > $\mathrm{C}-\mathrm{H}>\mathrm{N}-\mathrm{H}$ as shown in Table 3. Some of our observed bond lengths are quite comparable to those reported by $\mathrm{Zhu}^{44}$ and $\mathrm{Zhou}^{71}$ on their carbon model system.

In Tables 4 and 5 , the calculated energy of chemisorption $\mathrm{E}_{\text {ads }}$ in $\mathrm{Kcal} / \mathrm{mol} / \mathrm{H}$ is tabulated for one hydrogen atom, and two hydrogen atoms, respectively. When hydrogen is chemisorbed directly on boron, the $\mathrm{E}_{\mathrm{ads}}$ is only slightly increased compare to the unsubstituted graphite model, and when directly on nitrogen, it is substantially decreased. However, when hydrogen is adsorbed on a carbon adjacent to boron or nitrogen, $\mathrm{E}_{\mathrm{ads}}$ is increased and is greater than the unsubstituted value.

The potential energy diagram in Figure 2 can further illustrate this trend. The same trend is also observed for two hydrogen atoms chemisorbed on the graphite models. Thus, $\mathrm{E}_{\text {ads }}$ is much higher when hydrogen is on adjacent carbon to boron or nitrogen compare to directly on boron or nitrogen, and it is highest when 2 hydrogens are on carbons adjacent to a boron and a nitrogen. The $\mathrm{E}_{\mathrm{ads}}$ calculation indicates the doped carbon is favorable for hydrogen adsorption, which is in agreement with the experimental observations. The calculation results further shed light on the most favorable and possible sites with which the spiltover hydrogen atoms bind.

\section{Conclusions}

In this study, we have demonstrated the synthesis of Band $\mathrm{N}$-doped microporous carbon via a substitution reaction. The obtained B- and N-doped microporous carbon exhibited much higher surface area than previously reported high-surface area B- and N-doped mesoporous carbon, carbon

Table 5. Calculated Eads for Chemisorption of 2 Hydrogens

\begin{tabular}{cc}
\hline \multicolumn{1}{c}{ Graphite models } & $\begin{array}{c}E_{\mathrm{ads}} \\
(\mathrm{Kcal} / \mathrm{mol} / \mathrm{H})\end{array}$ \\
\hline B-with 1 hydrogen on boron \& 1 hydrogen & -35.23 \\
on adjacent carbon & -25.67 \\
C-with 1 hydrogen on nitrogen \& 1 hydrogen & \\
on adjacent carbon & -29.69 \\
F-with 1 hydrogen on boron \& 1 hydrogen on nitrogen & -47.16 \\
F-with 1 hydrogen on carbon adj. to boron \& & \\
1 hydrogen on carbon adj. to nitrogen & \\
\hline
\end{tabular}


nanotubes, amorphous carbon, and activated $\mathrm{BN}$ due to the application of a microporous carbon template with high-surface area and porosity. The hydrogen storage tests showed B- and N-doped microporous carbon had a 53\% higher storage capacity than the pure carbon with a similar surface area. Doping of $\mathrm{Ru}$ on $\mathrm{B}$ - and $\mathrm{N}$-doped microporous carbon further significantly enhanced its hydrogen uptake by a factor of 2.2 due to the spillover effect. Hydrogen adsorption on B- and N-doped microporous carbon via spillover has been further studied by molecular orbital calculations, and the experimental results are in agreement with the theoretical predictions on the effects of B- and N-substitution.

\section{Acknowledgements}

The authors acknowledge the funding provided by the US Department of Energy's Office of Energy Efficiency and Renewable Energy within the Hydrogen Sorption Center of Excellence (HS CoE) and from NSF.

\section{Literature Cited}

1. Lu A-H, Schüth F. Nanocasting: A Versatile strategy for creating nanostructured porous materials. Adv Mater. 2006;18:1793-1805.

2. Lee J, Kim J, Hyeon T. Recent progress in the synthesis of porous carbon materials. Adv Mater. 2006;18:2073-2094.

3. Iijima S. Helical microtubules of graphitic carbon. Nature. 1991; 354:56-58.

4. Ma Z, Kyotani T, Liu Z, Terasaki O, Tomita A. Very high surface area microporous carbon with a three-dimensional nano-array structure: Synthesis and its molecular structure. Chem Mater. 2001;13: 4413-4415.

5. Johnson SA, Brigham ES, Olliver PJ, Mallouk TE. Effect of micropore topology on the structure and properties of zeolite polymer replicas. Chem Mater. 1997;9:2448-2458.

6. Rodriguez-Mirasol J, Cordero T, Radovic LR, Rodriguez JJ. Structural and textural properties of pyrolytic carbon formed within a microporous zeolite template. Chem Mater. 1998;10:550-558.

7. Yang RT, Adsorbents: fundamentals and applications. New York: Wiley; 2003.

8. Gaslain FOM, Parmentier J, Valtchev VP, Patarin J. First zeolite carbon replica with a well resolved X-ray diffraction pattern. Chem Commun. 2006;991-993.

9. Wang L, Zhang J, Su DS, Ji Y, Cao X, Xiao F-S. Simple preparation of honeycomb-like macrostructured and microporous carbons with high performance in oxidative dehydrogenation of ethylbenzene. Chem Mater. 2007;19:2894-2897.

10. Jun S, Joo SH, Ryoo R, Kruk M, Jaroniec M, Liu Z, Ohsuna T, Terasaki O. Synthesis of new, nanoporous carbon with hexagonally ordered mesostructure. J Am Chem Soc. 2000;122:10712-10713.

11. Han S, Hyeon T. Simple silica-particle template synthesis of mesoporous carbons. Chem Commun. 1999;1955-1956.

12. Kruk M, Jaroniec M, Ryoo R, Joo SH. Characterization of ordered mesoporous carbons synthesized using MCM-48 silicas as templates. J Phys Chem. B 2000;104:7960-7968.

13. Han W, Bando Y, Kurashima K, Sato T. Boron-doped carbon nanotubes prepared through a substitution reaction. Chem Phys Lett. 1999;299:368-373.

14. Shirasaki T, Derré A, Ménétrier M, Tressaud A, Flandrois S. Synthesis and characterization of boron-substituted carbons. Carbon. 2000;38:1461-1467.

15. Borowiak-Palen E, Pichler T, Fuentes GG, Graff A, Kalenczuk RJ, Knupfer M, Fink J. Efficient production of B-substituted single-wall carbon nanotubes. Chem Phys Lett. 2003;378:516-520.

16. McGuire K, Gothard N, Gai PL, Dresselhaus MS, Sumanasekera G, Rao AM. Synthesis and raman characterization of boron-doped single-walled carbon nanotubes. Carbon. 2005;43:219-227.

17. Blackburn JL, Yan Y, Engtrakul C, Parilla PA, Jones K, Gennett T, Dillon AC, Heben MJ. Synthesis and characterization of borondoped single-wall carbon nanotubes produced by the laser vaporization technique. Chem Mater. 2006;18:2558-2566.
18. Viswanathan B, Sankaran M. Hydrogen storage in boron substituted carbon nanotubes. Carbon. 2007;45:1628-1635.

19. Lahaye J, Nansé G, Bagreev A, Strelko V. Porous structure and surface chemistry of nitrogen containing carbons from polymers. Carbon. 1999;37:585-590.

20. Yang C. M, El-Merraoui M, Seki H, Kaneko K. Characterization of nitrogen-alloyed activated carbon fiber. Langmuir. 2001;17:675680.

21. Raymundo-Piñero E, Cazorla-Amorós D, Linares-Solano A, Find J, Wild U, Schlögl R. Structural characterization of N-containing activated carbon fibers prepared from a low softening point petroleum pitch and a melamine resin. Carbon. 2002;40:597-608.

22. Hou P-X, Orikasa H, Yamazaki T, Matsuoka K, Tomita A, Setoyama N, Fukushima Y, Kyotani T. Synthesis of nitrogen-containing microporous carbon with a highly ordered structure and effect of nitrogen doping on $\mathrm{H}_{2} \mathrm{O}$ adsorption. Chem Mater. 2005; 17:5187-5193.

23. Yang Z, Xia Y, Sun X, Mokaya R. Preparation and hydrogen storage properties of zeolite-templated carbon materials nanocast via chemical vapor deposition: effect of the zeolite template and nitrogen doping. J Phys Chem B. 2006;110:18424-18431.

24. Liu J, Webster S, Carrol DL. Temperature and flow rate of $\mathrm{NH}_{3}$ effects on nitrogen content and doping environments of carbon nanotubes grown by injection CVD method. J Phys Chem B. 2005;109:15769-15744.

25. Weng-Sieh Z, Zettl A, Gronsky R. Synthesis of BxCyNz nanotubules. Phys Rev. B 1995;51:11229-11232.

26. Redlich P, Loeffler J, Ajayan PM, Bill J, Aldinger F, Ruehle M. B$\mathrm{C}-\mathrm{N}$ nanotubes and boron doping of carbon nanotubes. Chem Phys Lett. 1996;260:465-470.

27. Enouz S, Stéphan O, Glerup M, Cochon JL, Colliex C,LoiseauA. Synthesis and structure of BN-doped multi-walled and single-walled carbon nanotubes. Phys Stat Sol (b). 2006;243:3246-3251.

28. Zhang Y, Gu H, Suenaga K, Iijima S. Heterogeneous growth of B-C-N nanotubes by laser ablation. Chem Phys Lett. 1997;279:264-269.

29. Golberg D, Bando Y, Han W, Kurashima K, Sato T. Single-walled B-doped carbon, B/N-doped carbon and $\mathrm{BN}$ nanotubes synthesized from single-walled carbon nanotubes through a substitution reaction. Chem Phys Lett. 1999;308:337-342.

30. Han W, Kohler-Redlich P, Ernst F, Rühle M. Formation of (BN)xCy and $\mathrm{BN}$ nanotubes filled with boron carbide nanowires. Chem Mater. 1999;11:3620-3623.

31. Raidongia K, Jagadeesan D, Upadhyay-Kahaly M, Waghmare UV, Pati SK, Eswaramoorthy M, Rao CNR. Synthesis, structure and properties of homogeneous $\mathrm{BC}_{4} \mathrm{~N}$ nanotubes. J Mater Chem. 2008;18:83-90.

32. Terrones M, Benito AM, Manteca-Diego C, Hsu WK, Osman OI, Hare JP, Reid DG, Terrones H, Cheetham AK, Prassides K, Kroto HW, Walton DRM. Pyrolytically grown $\mathrm{BxCyNz}$ nanomaterials: nanofibres and nanotubes. Chem Phys Lett. 1996;257:576-582.

33. Panchakaria LS, Govindaraj A, Rao CNR. Nitrogen- and borondoped double-walled carbon nanotubes. ACS Nano. 2007;1:494-500.

34. Yu J, Bai XD, Ahn J, Yoon SF, Wang EG. Highly oriented rich boron B-C-N nanotubes by bias-assisted hot filament chemical vapor deposition. Chem Phys Lett. 2000;323:529-533.

35. Yang Q, Xu W, Tomita A, Kyotani T. Template synthesis of double coaxial carbon nanotubes with nitrogen-doped and boron-doped multiwalls. J Am Chem Soc. 2005; 127:8956-8957.

36. Ozaki J-I, Kimura N, Anahara T, Oya A. Preparation and oxygen reduction activity of BN-doped carbons. Carbon. 2007;45:1847-1853.

37. Konno H, Shiba K, Kaburagi Y, Hishiyama Y, Inagaki M. Carbonization and graphitization of Kapton-type polyimide film having boron-bearing functional groups. Carbon. 2001;39:1731-1740.

38. Vinu A, Terrones M, Golberg D, Hishita S, Ariga K, Mori T. Synthesis of mesoporous $\mathrm{BN}$ and $\mathrm{BCN}$ exhibiting large surface areas via templating methods. Chem Mater. 2005;17:5887-5890.

39. Gaussian 03, Revision C.02, Frisch MJ, Trucks GW, Schlegel HB et al., Wallingford, CT: Gaussian; 2004.

40. Cerius2, version 4.6, Accelrys, San Diego, CA.

41. Han W, Brutchey R, Tilley TD, Zettl A. Activated boron nitride derived from activated carbon. Nano Lett. 2004;4:173-176.

42. Chung TCM, Jeong Y, Che Q, Kleinhammes A, Wu Y. Synthesis of microporous boron-substituted carbon (B/C) materials using polymeric precursors for hydrogen physisorption. J Am Chem Soc. 2008;130:6668-6669. 
43. Zhou L, Zhou Y, Sun Y. A comparative study of hydrogen adsorption on superactivated carbon versus carbon nanotubes. Inter J Hydrogen Energy. 2004;29:475-479.

44. Zhu ZH, Lu GQ, Hatori H. New insights into the interaction of hydrogen atoms with boron-substituted carbon. J Phys Chem B. 2006;110:1249-1255.

45. Agrawal R, Offutt M, Ramage MP. Hydrogen economy - an opportunity for chemical engineers? AIChE J. 2005;51:1582-1589.

46. Lueking A, Yang RT. Hydrogen spillover from a metal oxide catalyst onto carbon nanotubes-implications for hydrogen storage. J Catal. 2002;206:165-168.

47. Lueking A, Yang RT. Hydrogen storage in carbon nanotubes: residual metal content and pretreatment temperature. AIChE J. 2003; 49:1556-1568.

48. Lachawiec AJ, Qi GS, Yang RT. Hydrogen storage in nanostructured carbons by spillover: Bridge-building enhancement. Langmuir. 2005;21:11418-11424.

49. Li YW, Yang RT. Significantly enhanced hydrogen storage in metal-organic frameworks via spillover. J Am Chem Soc. 2006;128:726-727.

50. Li YW, Yang RT. Hydrogen storage in metal-organic and covalentorganic frameworks by spillover. AIChE J. 2008;54:269-279.

51. Li YW, Yang RT. Hydrogen storage in low silica type X zeolites. J Phys Chem B. 2006;110:17175-17181.

52. Wang L, Yang RT. New sorbents for hydrogen storage by hydrogen spillover - a review. Energy Environ Sci. 2008;10.1039/b807957a.

53. Robell AJ, Ballou EV, Boudart M. Surface diffusion of hydrogen on carbon. J Phys Chem. 1964;68:2748-2753.

54. Srinivas ST, Rao PK. Direct observation of hydrogen spillover on carbon-supported platinum and its influence on the hydrogenation of benzene. J Catal. 1994;148:470-477.

55. Conner WC Jr, Falconer JL. Spillover in heterogeneous catalysis. Chem Rev. 1995;95:759-788.

56. Lupu D, Biris AR, Misan I, Jianu A, Holzhuter G, Burkel E. Hydrogen uptake by carbon nanofibers catalyzed by palladium. Int J Hydrogen Energy. 2004;29:97-102.

57. Zacharia R, Kim KY, Fazle Kibria AKM, Nahm KS. Enhancement of hydrogen storage capacity of carbon nanotubes via spill-over from vanadium and palladium nanoparticles. Chem Phys Lett. 2005;412:369-375.

58. Zielinski M, Wojcieszak R, Monteverdi S, Mercy M, Bettahar MM. Hydrogen storage on nickel catalysts supported on amorphous activated carbon. Catal Comm. 2005;6:777-783.

59. Back C, Sandi G, Prakash J, Hranisavljevic J. Hydrogen sorption on palladium-doped sepiolite-derived carbon nanofibers. J Phys Chem B. 2006;110:16225-16231.
60. Anson A, Lafuente E, Urriolabeitia E, Navarro R, Benito AM, Maser WK, Martinez MT. Hydrogen capacity of palladium-loaded carbon materials. J Phys Chem B. 2006:110:6643-6648.

61. Li YW, Yang RT. Hydrogen storage on platinum nanoparticles doped on superactivated carbon. J Phys Chem C. 2007;111:1108611094.

62. Wang L, Yang RT. Hydrogen storage properties of carbons doped with ruthenium, platinum, and nickel nanoparticles. J Phys Chem. C 2008;10.1021/jp803093w.

63. Orimo S, Matsushima T, Fujii H, Fukunaga T, Majer G. Hydrogen desorption property of mechanically prepared nanostructured graphite. J Appl Phys. 2001;90:1545-1549.

64. Zhong ZY, Xiong ZT, Sun LF, Luo JZ, Chen P, Wu Z, Lin J, Tan KL. Nanosized nickel (or cobalt)/graphite composites for hydrogen storage. J Phys Chem. B 2002;106:9507-9513.

65. Yoo E, Gao L, Komatsu T, Yagai N, Arai K, Yamazaki T, Matsuishi K, Matsumoto T, Nakamura J. Atomic hydrogen storage in carbon nanotubes promoted by metal catalysts. J Phys Chem B. 2004;108:18903-18907.

66. Chen L, Cooper AC, Pez GP, Cheng H. Mechanistic study on hydrogen spillover onto graphitic carbon materials. J Phys Chem C. 2007;111:18995-19000.

67. Mitchell PCH,Ramirez-CuestaAJ Parker SF, Tomkinson J, Thompsett D. Hydrogen spillover on carbon-supported metal catalysts studied by inelastic neutron scattering. surface vibrational states and hydrogen riding modes. J Phys Chem B. 2003;107:6838-6845.

68. Mitchell PCH, Ramirez-Cuesta AJ, Parker SF, Tomkinson J. Inelastic neutron scattering in spectroscopic studies of hydrogen on carbon-supported catalysts-experimental spectra and computed spectra of model systems. J Mol Struct. 2003;651-653:781-785.

69. Kim YH, Zhao Y, Williamson A, Heben MJ, Zhang SB. Nondissociative adsorption of $\mathrm{H}_{2}$ molecules in light-element-doped fullerenes. Phys Rev Lett. 2006;96:016102.

70. Sankaran M, Viswanathan B. The role of heteroatoms in carbon nanotubes for hydrogen storage. Carbon. 2006;44:2816-2821.

71. Zhou Z, Gao X, Yan J, Song D. Doping effects of B and N on hydrogen adsorption in single-walled carbon nanotubes through density functional calculations. Carbon. 2006;44:939-947.

72. Zhu ZH, Hatori $\mathrm{H}$, Wang SB, Lu GQ. Insights into hydrogen atom adsorption on and the electrochemical properties of nitrogensubstituted carbon materials. J Phys Chem. B 2005;109:1674416749.

Manuscript received Aug. 4, 2008, and revision received Jan. 8, 2009. 